\title{
Thermal Neutron Capture Cross Sections of Tellurium Isotopes.
}

\author{
I. Tomandl, J. Honzátko \\ Nuclear Physics Institute, $25068 \check{R} e \breve{z}$, Czech Republic \\ T. von Egidy, H.-F. Wirth \\ Physik-Department, Technische Universität München, D-85748 Garching, Germany \\ T. Belgya, M. Lakatos, L. Szentmiklósi, Zs. Révay, G.L. Molnár \\ Institute of Isotope and Surface Chemistry, Chemical Research Centre \\ of Hungarian Academy of Sciences, H-1525 Budapest, Hungary \\ R.B. Firestone \\ Lawrence Berkeley National Laboratory, CA 94720, Berkeley, USA \\ V. Bondarenko \\ Institute of Solid State Physics, University of Latvia, Riga, LV-1063,Latvia
}

(Dated: September 2, 2003)

\begin{abstract}
New values for thermal neutron capture cross sections of the tellurium isotopes ${ }^{122} \mathrm{Te},{ }^{124} \mathrm{Te}$, ${ }^{125} \mathrm{Te},{ }^{126} \mathrm{Te},{ }^{128} \mathrm{Te}$ and ${ }^{130} \mathrm{Te}$ are reported. These values are based on a combination of newly determined partial $\gamma$-ray cross sections obtained from experiments on targets contained natural Te and $\gamma$ intensities per capture of individual Te isotopes. Isomeric ratios for the thermal neutron capture on the even tellurium isotopes are also given.
\end{abstract}

PACS numbers: 25.40.Lw, 27.60.+j

Reaction cross sections belong to the basic quantities in nuclear physics. Their precise values are important for the evaluation of many experiments as well as various applications. Thermal neutron capture cross sections are one of the most utilized quantities. In the last decades, many measurements were carried out to obtain precise values for all stable isotopes. In spite of this large effort, there are still some uncertainties in the tables of thermal neutron cross sections.

Our publication reports new thermal neutron capture cross section values leading to the ground or isomeric states for all stable Te isotopes except for ${ }^{120} \mathrm{Te}$ and ${ }^{123} \mathrm{Te}$. In addition several elemental partial gamma-ray cross sections are reported for the stable Te isotopes except for ${ }^{120} \mathrm{Te}$. The summary of previously published thermal neutron cross sections is given in Table I. These values were measured by means of activation [1-6] and pile oscillator[7] techniques. Besides these measured values also compiled values given in the BNL atlas of neutron cross sections [8] are shown in this table.

In the present work we used a combination of $\gamma-$ ray emission probabilities per capture, or absolute $\gamma$ ray intensities $\mathrm{I}_{\gamma}$ determined in $(\mathrm{n}, \gamma)$ measurements with highly enriched targets, and elemental partial $\gamma$-ray production cross sections $\sigma_{\gamma}^{\text {elem }}$ of a natural Te target for the determination of the total neutron capture cross sections of tellurium isotopes.

The experiments with the enriched targets were performed at the thermal neutron facility in Rež [12]. The ${ }^{125} \mathrm{Te}(\mathrm{n}, \gamma)$ experiments were performed at PSI, Villigen, Switzerland [13]. Absolute $\gamma$-ray intensities per neutron capture were determined using two methods. In the cases
${ }^{128} \mathrm{Te}[14]$ and ${ }^{130} \mathrm{Te}[15]$ the known $\gamma$ intensities of lines following the $\beta$ decay of the produced isotopes were applied for the calibration. In other cases we made the assumption that the observed percentages of the sum of the ground- and isomeric-state populations in our recent experiments amount to $90 \pm 10 \%$ for each neutron capture in the cases of ${ }^{124} \mathrm{Te}$ [16] and ${ }^{126} \mathrm{Te}$ [17], $80 \pm 15 \%$ for ${ }^{122} \mathrm{Te}$ [18] and $80 \pm 12 \%$ for ${ }^{125} \mathrm{Te}$ [13]. The assumptions of the observed percentages are based on the estimation of the most probable value of the lost intensity ending at the ground or isomeric state. To obtain these values of the lost intensities we combined the detection limits of the individual experiments, the systematics of tellurium isotopes, the population-depopulation balances of low-lying levels and the Two-Step Cascade (TSC) spectra [12], from which the percentage of the two-step cascade intensity of unresolved weak transitions can be extracted. These procedure can be checked by means of the heavy tellurium isotopes ${ }^{126} \mathrm{Te},{ }^{128} \mathrm{Te}$ and ${ }^{130} \mathrm{Te}$ which can be normalized via a beta-decay. A good agreement for all three isotopes between these two normalizations validate our procedure of normalization of the light tellurium isotopes.

Partial $\gamma$-ray production cross sections for the strongest lines of each major contributing isotope of almost all elements have been determined [19, 20] at the old Budapest PGAA facility [21]. The relevant value for Te was 2.4(2) b for the $603 \mathrm{keV}$ gamma-ray from the ${ }^{123} \mathrm{Te}(\mathrm{n}, \gamma)$ isotope $[19,20]$. However its large uncertainty (due to low counting statistics) was not good enough for our purpose. Therefore, it was necessary to remeasure this number with substantially higher precision and pro- 
TABLE I: Summary of published thermal neutron cross sections of tellurium isotopes leading to ground and metastable states in barns. Note that the products without index label the total thermal neutron cross sections $\sigma^{g+m}$.

\begin{tabular}{|c|c|c|c|c|c|c|c|c|c|c|c|}
\hline Target & Product & Ser47 [1] & Pom52 [7] & Gvo59 [2] & Seh62 [3] & Man62 [4] & Ric68 [5] & $\operatorname{Max} 69[6]$ & BNL81 [8] & Hon93 [10] & Alp95 [11] \\
\hline \multirow[t]{2}{*}{ 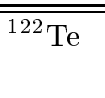 } & ${ }^{123} \mathrm{Te}$ & & $2.7(9)$ & & & & & & $3.4(5)^{a)}$ & & \\
\hline & ${ }^{123} \mathrm{Te}^{m}$ & & & & & & & & $1.1(5)$ & & $0.44(3)$ \\
\hline \multirow{2}{*}{${ }^{124} \mathrm{Te}$} & ${ }^{125} \mathrm{Te}$ & & $6.5(13)$ & & & & & & $6.8(13)$ & & \\
\hline & ${ }^{125} \mathrm{Te}^{m}$ & & & $0.040(25)$ & & & & & $0.040(25)$ & $\geq 1.0$ & $1.12(7)$ \\
\hline${ }^{125} \mathrm{Te}$ & ${ }^{126} \mathrm{Te}$ & & $1.49(15)$ & & & & & & $1.55(16)$ & & \\
\hline \multirow[t]{3}{*}{${ }^{126} \mathrm{Te}$} & ${ }^{127} \mathrm{Te}$ & & $0.77(19)$ & & & & & & $1.04(15)$ & & \\
\hline & ${ }^{127} \mathrm{Te}^{g}$ & $0.78(16)$ & & & & $1.034(155)$ & & & $0.90(15)$ & & \\
\hline & ${ }^{127} \mathrm{Te}^{m}$ & $0.073(15)$ & & & & & & & $0.135(23)$ & & $0.063(6)$ \\
\hline \multirow[t]{3}{*}{${ }^{128} \mathrm{Te}$} & ${ }^{129} \mathrm{Te}$ & & $0.3(3)$ & & & & & & $0.215(8)$ & & \\
\hline & ${ }^{129} \mathrm{Te}^{g}$ & $0.133(27)$ & & & & $0.178(27)$ & & $0.200(8)$ & $0.200(8)$ & & \\
\hline & ${ }^{129} \mathrm{Te}^{m}$ & $0.015(3)$ & & & & & & $0.0161(7)$ & $0.015(1)$ & & $0.027(2)$ \\
\hline \multirow[t]{3}{*}{${ }^{130} \mathrm{Te}$} & ${ }^{131} \mathrm{Te}$ & & $0.5(3)$ & & & & & & & & \\
\hline & ${ }^{131} \mathrm{Te}^{g}$ & $0.222(44)$ & & & $0.27(6)$ & $0.161(24)$ & $0.26(8)$ & & $0.27(2)$ & & \\
\hline & ${ }^{131} \mathrm{Te}^{m}$ & $<0.008(3)$ & & & $0.04(1)$ & & & & $0.02(1)$ & & \\
\hline
\end{tabular}

a) Updated value is $3.9(5) \mathrm{b}$, see Ref. [9].

vide partial cross section values for at least one gamma line from each of the other Te isotopes as well.

The new $\sigma_{\gamma}^{\text {elem }}$ values for Te were determined by using the internal standardisation method [20, 22]. The measurements were performed at the new cold neutron PGAA facility [23] of the Budapest Research Reactor. The neutron flux on target amounted to $5 \times 10^{7} \mathrm{~cm}^{-2} \mathrm{~s}^{-1}$, 25 times higher than that of the old guided thermal beam [21].

We accumulated an $(n, \gamma)$ spectrum of $0.312 \mathrm{~g}$ natural tellurium-oxide powder to determine the relative intensities of gamma-rays in the natural Te. The sample was packed in thin Teflon bag and had dimensions $17 \times 17 \times 1 \mathrm{~mm}^{3}$. It was placed in the PGAA sample holder and irradiated for about $230,000 \mathrm{~s}$.

In separate experiments with 0.194 g natural telluriumoxide dissolved in $2.151 \mathrm{~g} 20 \mathrm{~m} \%$ hydrochloride acid (in contrast to the 1000 ppm ICP standard used in refs. $[19,20])$, we re-determined the elemental partial $\gamma$-ray cross section for the $603 \mathrm{keV}$ transition from the ${ }^{123} \mathrm{Te}(\mathrm{n}, \gamma)$ reaction. The solution was kept in a thinwalled cylindrical Teflon container. Two (n, $\gamma)$ spectra were accumulated for about $74600 \mathrm{~s}$ and $1000 \mathrm{~s}$, respectively. From the shorter experiment we cross-checked the hydrogen concentration of the solution relative to its chlorine content. We found that it corresponded to the nominal concentration of the $20 \mathrm{~m} \%$ hydrochloride acid. From the longer experiment we determined the $\sigma_{\gamma}^{\text {elem }}$ for the $603 \mathrm{keV}^{123} \mathrm{Te}(\mathrm{n}, \gamma) \gamma$-ray using several comparator $\gamma$ rays from the ${ }^{35} \mathrm{Cl}(\mathrm{n}, \gamma)$ reaction and the only $\gamma$-ray from the ${ }^{1} \mathrm{H}(\mathrm{n}, \gamma)$ reaction.

The new elemental partial cross sections for the $603 \mathrm{keV}{ }^{124} \mathrm{Te} \gamma$-ray calculated from each comparator line are listed in Table II. The unweighted average and
TABLE II: Deterimination of the elemental partial cross section of the $603 \mathrm{keV} \gamma$-ray from the ${ }^{123} \mathrm{Te}(\mathrm{n}, \gamma){ }^{124} \mathrm{Te}$ reaction on natural tellurium.

\begin{tabular}{cccc} 
Comparator lines & \multicolumn{3}{c}{$603 \mathrm{keV} \gamma$ ray } \\
\hline Element & $E_{\gamma}(\mathrm{keV})$ & $\sigma_{\gamma}($ barn $)$ & unc. (\%) \\
\hline $\mathrm{H}$ & 2223 & 2.912 & 1.15 \\
$\mathrm{Cl}$ & 517 & 2.975 & 0.90 \\
$\mathrm{Cl}$ & $787^{*}$ & 2.838 & 0.57 \\
$\mathrm{Cl}$ & 1951 & 2.912 & 0.98 \\
$\mathrm{Cl}$ & 1959 & 2.906 & 1.14 \\
\hline
\end{tabular}

* Sum of 786 and $788 \mathrm{keV}$ peaks.

its external standard uncertainty is $2.908 \pm 0.049 \mathrm{~b}$. Using the partial cross section of the $603 \mathrm{keV}$ and the relative peak intensities obtained from the spectrum of the natural tellurium oxide we have determined the elemental partial production cross sections for some of the most intense $\gamma$-rays of the tellurium isotopes.

We stress that these values are independent from the energy distribution of the neutron beam due to the $\frac{1}{v}$ dependence [20]. All Westcott g-factors are practically unity. The only exception is ${ }^{123} \mathrm{Te}$, which has the value of 1.013 at $300 \mathrm{~K}$ according to Ref. [24]. Since this factor is unity within the overall experimental uncertainty, it has been neglected.

Combining $\check{R}$ ž and Budapest results one can calculate the thermal neutron capture cross sections for the tellurium isotopes from the absolute $\gamma$ intensities $I_{\gamma}$ (i.e. emission probabilities per capture) and the new elemental partial $\gamma$-ray cross sections $\sigma_{\gamma}^{\text {elem }}$ measured at Budapest 
TABLE III: Calculation of thermal neutron capture cross sections using new $\gamma$-intensities and partial elemental cross sections.

\begin{tabular}{|c|c|c|c|c|c|}
\hline $\begin{array}{l}\text { Target } \\
\theta(\%)^{e)} \\
\text { ref. } \mathrm{I}_{\gamma} \\
\delta \sigma_{n \gamma}^{s y s t}(\%) \\
\end{array}$ & $\begin{array}{c}\gamma \text {-lines } \\
(\mathrm{keV})\end{array}$ & $\begin{array}{l}\mathrm{I}_{\gamma} \\
(\%)\end{array}$ & $\begin{array}{l}\sigma_{\gamma}^{\text {elem }} \\
(\mathrm{mb})\end{array}$ & $\begin{array}{ll}\sigma_{n \gamma} & \\
(\mathrm{b}) & \\
& \end{array}$ & $\begin{array}{l}\text { BNL } \sigma_{n} \\
\text { (b) }\end{array}$ \\
\hline${ }^{122} \mathrm{Te}$ & 440 & $11.1(3)$ & $11.47(19)$ & $4.05(14)$ & \\
\hline $2.55(12)$ & 897 & $1.92(17)$ & $2.06(17)$ & $4.21(51)$ & \\
\hline$[18]$ & 5170 & $3.12(6)$ & $3.08(21)$ & $3.87(29)$ & \\
\hline 15 & average & & & $4.0(6)$ & $3.9(5)$ \\
\hline${ }^{124} \mathrm{Te}$ & 380 & $8.47(6)$ & $25.1(7)$ & $6.25(17)$ & \\
\hline $4.74(14)$ & 427 & $6.96(3)$ & $20.1(2)$ & $6.09(8)$ & \\
\hline \multirow[t]{3}{*}[16]{} & 537 & $6.38(3)$ & $17.7(3)$ & $5.85(11)$ & \\
\hline & 693 & $6.27(4)$ & $20.1(6)$ & $6.76(22)$ & \\
\hline & 6533 & $3.53(7)$ & $9.5(9)$ & $5.68(55)$ & \\
\hline 10 & average & & & $6.1(7)$ & $6.8(13)$ \\
\hline${ }^{125} \mathrm{Te}$ & 666 & $67.0(34)$ & $59.3(3)$ & $1.25(6)$ & \\
\hline $7.07(15)$ & 695 & $6.57(33)$ & $6.94(31)$ & $1.49(10)$ & \\
\hline \multirow[t]{2}{*}[13]{} & 754 & $14.6(7)$ & $13.2(2)$ & $1.28(7)$ & \\
\hline & 6139 & $1.07(5)$ & $0.82(13)$ & $1.08(18)$ & \\
\hline 12 & average & & & $1.29(16)$ & $1.55(16)$ \\
\hline${ }^{126} \mathrm{Te}$ & 253 & $6.30(32)$ & $7.41(7)$ & $0.62(3)$ & \\
\hline $18.84(25)$ & 473 & $8.97(39)$ & $9.09(17)^{b)}$ & $0.53(2)$ & \\
\hline \multirow[t]{2}{*}[17]{} & 543 & $5.32(3)$ & $5.27(40)$ & $0.52(3)$ & \\
\hline & 4081 & $11.10(10)$ & $12.5(17)^{c)}$ & $0.59(7)$ & \\
\hline 10 & average & & & $0.55(6)$ & $1.04(15)$ \\
\hline${ }^{128} \mathrm{Te}$ & 180 & $44.0(4)$ & $33.7(17)$ & $0.241(7)$ & \\
\hline $31.74(8)$ & 359 & $7.60(8)$ & $5.82(47)$ & $0.241(20)$ & \\
\hline$[14]$ & 3703 & $10.3(1)$ & $7.66(66)^{d)}$ & $0.234(20)$ & \\
\hline 10 & average & & & $0.24(3)$ & $0.215(8)$ \\
\hline${ }^{130} \mathrm{Te}$ & 296 & $47.7(4)$ & $38.3(2)$ & $0.236(2)$ & \\
\hline $34.08(62)$ & 2287 & $26.8(3)$ & $21.3(3)$ & $0.233(4)$ & \\
\hline$[15]$ & 3347 & $32.0(3)$ & $27.6(17)$ & $0.253(16)$ & \\
\hline 6 & average & & & $0.24(2)$ & $0.29(6)$ \\
\hline
\end{tabular}

a) The systematic error $\delta \sigma_{n \gamma}^{s y s t}$ was added in quadrature for evaluation of the total uncertainty of the average.

b) A small contribution (3\%) from the ${ }^{122} \mathrm{Te}(\mathrm{n}, \gamma)$ reaction was subtracted.

c) A double escape contribution was subtracted (15 $\pm 5 \%)$.

d) A single escape contribution was subtracted (16 $\pm 5 \%$ ).

e) Abundances taken from Ref. [25].

using the equation:

$$
\sigma_{n \gamma}=\frac{\sigma_{\gamma}^{\text {elem }}}{\theta \times I_{\gamma}}
$$

where $\theta$ is the natural abundance of the given isotope [25]. In order to reduce the statistical uncertainties the total capture cross sections $\sigma_{n \gamma}$ were obtained as averaged values from at least three different lines for each isotope. These weighted averages are summarized in Table III.
TABLE IV: Isomeric ratios, $\sigma_{n \gamma}^{m} / \sigma_{n \gamma}^{g+m}$, for the odd Te isotopes.

\begin{tabular}{|c|c|c|c|c|}
\hline Product & Ref. [27] & Ref. [26] & This work $\mathrm{k}^{b}$ ) & Ref. [18] \\
\hline${ }^{123} \mathrm{Te}$ & & & $0.17(3)^{c}$ & $0.123(20)$ \\
\hline${ }^{125} \mathrm{Te}$ & & & $0.167(17)$ & $0.138(12)$ \\
\hline${ }^{127} \mathrm{Te}$ & $0.13(2)^{a}$ & $0.149(4)$ & $0.157(16)$ & $0.068(4)$ \\
\hline${ }^{129} \mathrm{Te}$ & & $0.124(8)$ & $0.111(10)$ & $0.108(10)$ \\
\hline${ }^{131} \mathrm{Te}$ & & $0.067(5)$ & $0.059(4)$ & $0.053(4)$ \\
\hline
\end{tabular}

${ }^{a}$ Calculated from the reported yield ratio, $\sigma_{n \gamma}^{m} / \sigma_{n \gamma}^{g}$.

${ }^{b}$ Calculated from the ratio of the intensity population of an isomeric state to the sum of the intensity population of an isomeric state and a ground state.

${ }^{c}$ Deduced from the normalized intensity population of the isomeric state.

All cross sections refer to $2200 \mathrm{~m} / \mathrm{s}$ neutrons in Table III.

Our new cross sections have smaller uncertainties than the ones given in the BNL report [8] except for ${ }^{125} \mathrm{Te}$ and ${ }^{128}$ Te. The new thermal neutron cross sections agree with the BNL report values within the given uncertainties except for ${ }^{126} \mathrm{Te}$. In this latter case the difference is quite large. As our values come from a consistent set of measurements at Rez and Budapest, it is reasonable to conclude that the new cross section value is the correct one.

Using the ratio of the population of the isomeric $11 / 2^{-}$ state and the ground state one can determine also the isomeric cross section. The total thermal neutron capture cross section of ${ }^{126} \mathrm{Te}$ mentioned above leads to significantly smaller value of the isomeric cross section, $\sigma_{n \gamma}^{m}=0.086 \pm 0.013 \mathrm{~b}$ than the value given in the BNL neutron cross section atlas [8], $\sigma_{n \gamma}^{m}=0.135 \pm 0.023 \mathrm{~b}$. On the other hand, the present value of the isomeric cross section is compatible with the recently published value $0.0625 \pm 0.0056 \mathrm{~b}$ [11]. It should be also noted that our isomeric ratio, $0.157 \pm 0.016$, agrees well with a very recent result of Reifarth and Käppeler [26], $0.149 \pm 0.004$. These recent works support the lower ground state cross section value for ${ }^{126} \mathrm{Te}$ obtained in our work.

Isomeric ratios calculated from our measurements for the other odd Te isotopes together with values reported in Refs. [26, 27] are given in the Table IV. In the last column the isomeric ratios from this work are compared with those published in Ref. [18] which had been based on the same experimental data. The differences are caused by different assumptions and approaches. The isomeric ratios reported in the paper on ${ }^{123} \mathrm{Te}$ [18] were deduced using the assumption of $100 \%$ of observed percentage for the population of the isomeric states and normalization via cross sections from the last BNL compilation [8]. On the other side, except for the ${ }^{123} \mathrm{Te}$ isotope, the values in this work are determined from the ratios of the total population of isomeric states to the total population of the ground and isomeric state. Thus, the new values of 
the isomeric ratios in this work do not depend on a used normalization procedure and any cross section. Uncertainties in the Table IV reflect also possible difference between observed percentages of populations of ground and isomeric states.

In the present work we have re-measured the partial elemental $(n, \gamma)$ cross section of ${ }^{123} \mathrm{Te}$ and determined accurate partial elemental $(n, \gamma)$ cross sections for $122,124,125,126,128,130 \mathrm{Te}$ for the first time. Using previously determined emission probabilities [13-17] we inferred new total capture cross sections for these isotopes. We found a significant difference only for ${ }^{126} \mathrm{Te}$. The new value is supported by several independent measurements of the ground state and isomer cross sections [11, 17, 26].

The authors appreciate the support of the EU FP 5 program (HPRI-CT-1999-00099) and two of the authors T. Belgya and Zs. Révay acknowledge the support of Bolyai Scholarship of HAS. Financial support has been also received from the Grant Agency of the Czech Republic (No. 202/03/0891, 202/99/D087).
[1] L. Seren, H.N. Friedlander, S.H. Turkel, Phys. Rev. 72, 888 (1947).

[2] Gvozdev, Zhurnal Eksperimentalnoi i Teoreticheskoi Fiziki 36, 632 (1959).

[3] M.L. Sehgal, Phys. Rev. 128, 761 (1962).

[4] S.K. Mangal, P.S. Gill, Nucl. Phys. 36, 542 (1962).

[5] M.D. Ricabarra, R. Turjanski, G.H. Ricabarra, C.B. Bigham, Can. J. Phys. 46, 2473 (1968).

[6] V. Maxia, E. Orvini, M.A. Rollier, Nuclear Science and Engineering, 35, 88 (1969).

[7] H. Pomerance, Phys. Rev. 88, 412 (1952).

[8] Neutron Cross Section, vol. 1, part A, edited by S.F. Mughabhab, M. Divideenam, N.E. Holden, Academic Press 1981, p. 12.

[9] S.F. Mughabghab, Thermal Neutron-Capture Cross Sections, Resonance Integrals and G-Factors, INDC(NDS)440 ;

[10] J. Honzátko, K. Konečný, I. Tomandl, Zeit. für Physik A 345, 401 (1993).

[11] V.G. Alpatov, A.V. Davydov, G.R. Kartashov, M.M. Korotkov, G.V. Kostina, P.A. Polozov, A.A. Sadovsky, Yadernaya Fizika, 58, 15 (1995).

[12] J. Honzátko, K. Konečný, I. Tomandl, J. Vacík, F. Bečvář, P. Cejnar, Nucl. Instr. Meth. A 376, 443 (1996).

[13] T. von Egidy, C. Doll,J. Jolie, N.V. Warr, J. Kern, M. Crittin, L. Genillioud, Nuclear Physics A 714, 355 (2003).

[14] H.-F. Wirth, T. von Egidy, I. Tomandl, J. Honzátko, D. Bucurescu, N. Mărginean, V.Yu. Ponomarev, R. Hertenberger, Y. Eisermann, G. Graw, Nuclear Physics A 716, 3 (2003).

[15] I. Tomandl, T. von Egidy, J. Honzátko, V. Bondarenko, H.-F. Wirth, D. Bucurescu, V.Yu. Ponomarev, G. Graw, R. Hertenberger, Y. Eisermann, S. Raman, Nuclear Physics A 717, 149 (2003).
[16] J. Honzátko, I. Tomandl, V. Bondarenko, D. Bucurescu, T. von Egidy, J. Ott, W. Schauer, H.-F. Wirth, C. Doll, A. Gollwitzer, G. Graw, R. Hertenberger, B.D. Valnion, Nuclear Physics A 645, 331 (1999).

[17] J. Honzátko et al., to be published.

[18] V. Bondarenko, T. von Egidy, J. Honzátko, I. Tomandl, D. Bucurescu, N. Mărginean, J. Ott, W. Schauer, H.F. Wirth, C. Doll, Nuclear Physics A 673, 85 (2000).

[19] Zs. Révay, G.L. Molnár, T. Belgya, Zs. Kasztovszky, R.B. Firestone, J. Rad. Nucl. Chem. 244, 383 (2000). Firestone, Appl. Rad. Isotopes 53, 527 (2000).

[20] Zs. Révay and G.L. Molnár, Radiochim. Acta 91, 361 (2003).

[21] T. Belgya, Zs. Révay, B. Fazekas, I. Héjja, L. Dabolczi, G. L. Molnár, Z. Kis, J. Östör, Gy. Kaszás in Proc. 9th International Symposium on Capture Gamma-Ray Spectroscopy and Related Topics, Budapest, Hungary, October 8-12, (Eds. G. Molnár, T. Belgya, Zs. Révay, Springer Verlag Budapest, Berlin, Heidelberg) (1997) p. 826.

[22] G.L. Molnar, Z. Révay, R.L. Paul, and R.M. Lindstrom, Journal of Radioanalytical and Nuclear Chemistry 234, 21(1998).

[23] T. Belgya, Z. Révay, P.P. Ember, J.L. Weil, G.L. Molnár and S. M. Qaim in Proc. 11th Int. Symp. on Capture Gamma-Ray Spectroscopy and related Topics (J. Kvasil, P. Cejnar, M.Krticka Eds., World Scientific, Singapore) (2003) p. 562

[24] Report INDC(NDS)-440, International Atomic Energy Agency, Vienna, 2003 p. 17. Available: http: www-nds.iaea.org (see Selected INDC Reports)

[25] K.J.R. Rosman and P.D.P. Taylor, Pure Appl. Chem. 70, 217 (1998).

[26] R. Reifarth and F. Käppeler, Phys. Rev. 66, 054605 (2002).

[27] B. Keisch, Phys. Rev. 129, 769 (1963). 